\title{
Cancer Risk in the Heart Failure Population: Epidemiology, Mechanisms, and Clinical Implications
}

\author{
Alessandra Cuomo ${ }^{1}$. Flora Pirozzi ${ }^{1}$. Umberto Attanasio ${ }^{1} \cdot$ Riccardo Franco $^{1}$ • Francesco Elia ${ }^{1}$ • Eliana De Rosa ${ }^{1}$. \\ Michele Russo $^{2}$ - Alessandra Ghigo ${ }^{2}$. Pietro Ameri ${ }^{3,4} \cdot$ Carlo Gabriele Tocchetti $^{1,5}$ (D) Valentina Mercurio ${ }^{1}$
}

Accepted: 5 November 2020 / Published online: 2 December 2020

(C) The Author(s) 2020

\begin{abstract}
Purpose of Review Along with population aging, the incidence of both heart failure (HF) and cancer is increasing. However, little is known about new-onset cancer in HF patients. This review aims at showing recent discoveries concerning this subset of patients. Recent Findings Not only cancer and HF share similar risk factors but also HF itself can stimulate cancer development. Some cytokines produced by the failing heart induce mild inflammation promoting carcinogenesis, as it has been recently suggested by an experimental model of HF in mice.

Summary The incidence of new-onset cancer is higher in HF patients compared to the general population, and it significantly worsens their prognosis. Moreover, the management of HF patients developing new-onset cancer is challenging, especially due to the limited therapeutic options for patients affected by both cancer and HF and the higher risk of cardiotoxicity from anticancer drugs.
\end{abstract}

Keywords Cardio-oncology $\cdot$ Cancer $\cdot$ Heart failure $\cdot$ Aging $\cdot$ Pathophysiology $\cdot$ Risk factors

\section{Introduction}

Cardiovascular disease and cancer are among the leading causes of death worldwide and the first two causes of death in the industrialized countries $[1,2]$. As the world population grows older, the incidence of both cancer and cardiovascular

This article is part of the Topical Collection on Cardio-oncology

Alessandra Cuomo, Flora Pirozzi, and Umberto Attanasio share first authorship

Carlo Gabriele Tocchetti

carlogabriele.tocchetti@unina.it

1 Department of Translational Medical Sciences, Federico II University, Naples, Italy

2 Department of Molecular Biotechnology and Health Sciences, Molecular Biotechnology Center, University of Torino, Torino, Italy

3 Cardiovascular Disease Unit, IRCCS Italian Cardiovascular Network, IRCCS Ospedale Policlinico San Martino, Genoa, Italy

4 Department of Internal Medicine, University of Genova, Genoa, Italy

5 Interdepartmental Center of Clinical and Translational Research, Federico II University, Naples, Italy diseases increases, and it is expected to keep on growing in the next decade [3]. Heart failure (HF) is the main complication of several cardiovascular diseases, and its incidence has grown enormously over the past decades $[4 \bullet \bullet, 5]$. It is also well known that cancer patients may develop HF due to cardiotoxic effects of antineoplastic treatments $[6 \bullet \bullet, 7 \bullet \bullet, 8]$. In order to provide better cardiological care to oncology patients, the field of cardio-oncology is acquiring an increasingly relevant role $[9,10]$. An important challenge in cardio-oncology is played by the onset of cancer in patients with preexisting HF [11]. While HF and cardiotoxicity induced by antineoplastic treatments have been largely studied over the years, there is scant data about cancer in preexisting HF patients. Moreover, patients with cardiac dysfunction are usually excluded from oncological clinical trials, due to the high prevalence of comorbidities and to their worse prognosis, compared to general population [1].

Aim of this review is to discuss epidemiologic evidence concerning cancer incidence in HF patients and the most recent findings on the possible mechanisms underlying the development of cancer in the setting of $\mathrm{HF}$, and to highlight challenging clinical implications. Figure 1 summarizes what we discuss in this review. 
Fig. 1 Graphic summary of the mechanisms and the clinical implications of the interaction between heart failure and cancer

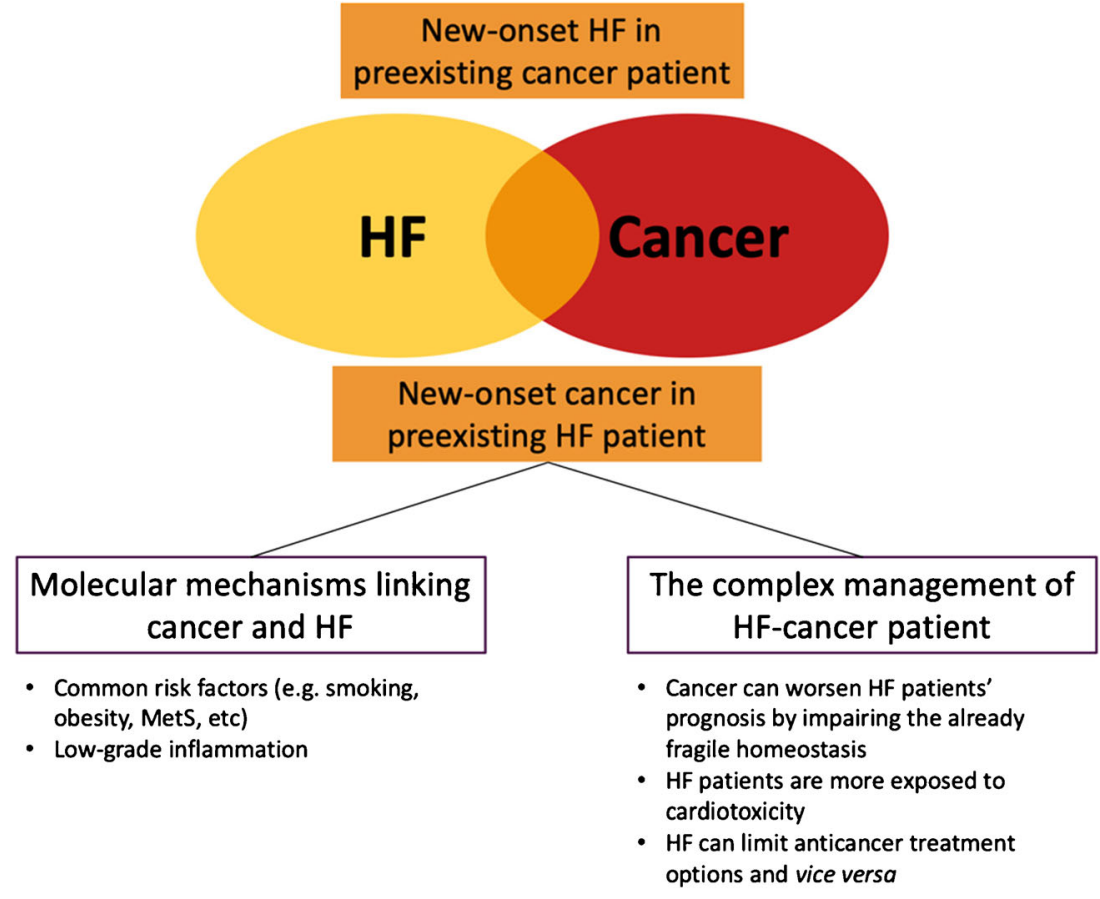

\section{Cancer in the Heart Failure Population: Epidemiology}

The incidences of both cancer and HF have increased in the past decades, and the risk of developing one of these two diseases augments over the lifespan [5]. Moreover, some studies have explored the incidence of cancer in patients with prior diagnosis of $\mathrm{HF}$, and it has been demonstrated that there is indeed an increased risk $[12 \bullet, 13 \bullet]$. Hasin and colleagues explored the risk of cancer incidence in patients with HF in a case-control study (the study included 596 patients with HF and 596 controls), showing that patients with HF had a $60 \%$ higher risk of developing malignancies, compared to non-HF controls. These results were confirmed when adjusting for some of the most common risk factors of both cancer and HF, such as BMI, smoking, and diabetes [14]. Gastrointestinal and male reproductive systems were the most incident neoplasms in the cohort. In a prospective cohort study, the same group then further explored the risk of cancer among a homogenous group of myocardial infarction (MI) survivors. The results of this study confirmed an increased risk of cancer among patients who developed HF after MI [15•]. Interestingly, beside cardiovascular mortality, stress echo (SE) has also been shown to predict cancer mortality, acting as a proxy of the shared risk factor milieu for cancer and cardiovascular (CV) death [16]. In particular, in the study from Carpeggiani and colleagues [16], cardiovascular mortality, cancer mortality, and non-cardiovascular and noncancer mortality were the primary endpoints, and SE was defined positive when at least 2 segments of the same vascular territory showed regional wall abnormalities. The peak wall motion score index was able to predict cardiovascular, cancer, and non-cardiovascular and non-cancer mortality. The authors speculate that the ability of SE in predicting cancer deaths could be linked to the common risk factors and pathophysiology shared between cancer and cardiovascular diseases [16].

In another manuscript, Banke and colleagues explored the incidence of cancer in a Danish group of 9307 patients affected from HF (predominantly with left ventricular ejection fraction $<45 \%$ ) and demonstrated a higher incidence rate of malignancies compared to the background population (188.9 vs 63.0 with $95 \%$ confidence interval), with an incidence rate ratio of 1.24 for cancer [13•]. Specifically, they found that the two most common new-onset malignancies in the examined HF population were the lung and skin, followed by both renal and urinary cancers (which had the same hazard ratio). Basically, all types of cancer were more frequent but prostate carcinoma [13•].

In addition, other important epidemiological data comes from a recent assessment on the prevention of renal and vascular end-stage disease (PREVEND) study population [17], in which, during a median follow-up of 11.5 years, 1132 subjects out of $8319(13.1 \%)$ were diagnosed with cancer. New-onset cancer cases were provided through the nationwide network and registry of histopathology and cytopathology data and archive in the Dutch PALGA [18]. Kaplan-Meier analysis according to NT-proBNP levels showed an increased risk of developing all-cause cancer, even when adjusted for common risk factors between $\mathrm{HF}$ and cancer [18].

When considering these data, it should be taken into account that there may be a surveillance bias, due to the fact that these study patients usually undergo an intense follow-up program that may lead to anticipate cancer diagnosis, sometimes discovering malignancies that would have gone undiscovered. 
Moreover, some of the most common therapies used to treat HF patients may play a role in revealing tumors otherwise asymptomatic (e.g., a latent intestinal neoplasm can induce bleeding due to anti-thrombotic therapy) [1]. Clinical presentations can also be difficult to distinguish between HF and cancer, since the 2 conditions share common symptoms (such as fatigue, dyspnea, weight loss, muscle wasting, edema) [1, 2]. This may delay the diagnosis of new-onset cancer in HF patients due to the overlap in clinical manifestation. Furthermore, CV function and predictors of exercise capacity have been shown to be impaired in patients with cancer per se [19]. Hence, symptoms due to a tumor may overlap with those of HF and be attributed to heart disease. This may even delay cancer diagnosis, as symptoms might be thought of as due to advancing disease rather than new cancer [1].

\section{Mechanisms of Cancer Development in Heart Failure}

Important pathophysiologic mechanisms connect cancer and $\mathrm{HF}$ and may explain the higher incidence of cancer in $\mathrm{HF}$ patients compared to the general population. First, there are some common risk factors between these two diseases, such as aging, smoking, and metabolic syndrome (MetS) with its components, including obesity and insulin resistance [20]. Moreover, some of the most common mechanisms involved in HF may also have a role in neoplasm growth and dissemination. Finally, another factor to take into account is the lowgrade inflammation state typical of HF patients which may constitute a substrate for the development of cancer in these patients [21].

In particular, the cumulative risk of developing chronic diseases increases with aging, with involvement of degenerative mechanisms such as oxidative stress and cellular senescence, which can contribute to the development of cardiovascular diseases and cancer [22-24, 25•]. Additionally, the link between the use of tobacco and malignancies is well known and is globally considered one of the main causes of cancerrelated deaths. It has been estimated that approximately $25 \%$ of all cancers in men and $4 \%$ in women might be connected to smoking, and in both sexes, approximately $16 \%$ of cancers in more-developed countries and $10 \%$ in less-developed countries may be linked to tobacco use [26], which is also the most important risk factor in developing cardiovascular diseases and an independent risk factor for coronary artery disease [5].

MetS, defined as the presence of at least three conditions among central obesity, high blood pressure, dyslipidemia, and increased fasting glucose, is notoriously considered an important risk factor for cardiovascular diseases [27]. In addition, some findings demonstrate an association between both hyperglycemia [28] and dyslipidemia [29] and increased risk of developing certain types of tumor, while the presence of obesity not only increases the relative risk of developing cancer
[30] but also is associated with a higher rate of recrudescence or recurrence [31] and poorer prognosis [32].

Beside common risk factors, other pathophysiological mechanisms are shared by both cancer and HF. Hyperactivation of the sympathetic nervous system (SNS), the renin-angiotensin-aldosterone system (RAAS), and the natriuretic peptide system is among the hallmarks of HF and has been conjectured to possibly increase the risk of cancer [33-35]. When studying the SNS, great attention has been placed to the $\beta$-adrenergic receptor ( $\beta \mathrm{AR}$ ) regulation and activation, hypothesizing that an excess of their activity may lead to tumorigenesis through the $\beta$-arrestin- 1 signaling [36]; induce cell proliferation by means of molecular pathways such as CREB, NF-kB, and AP-1 [37]; and confer resistance to apoptosis via multiple mechanisms, i.e., inhibition of suppressor gene p53 [37], proapoptotic protein BAD [38], and anoikis [39]. Interestingly, beside playing a fundamental role in heart function, both $\beta 1$ and $\beta 2$ ARs are expressed in all cell cancer types and mediate cancer proliferation, hence $\beta$ blockers might be putative adjuvants for cancer treatment [40, 41], not only in cardioprotection from anticancer druginduced cardiotoxicity [42•, 43, 44•].

The SNS may also play a role in modifying the microenvironment in which cancer develops and grows [45], promoting neoplastic dissemination via tumor-associated macrophages [46] that can enhance peri- and intratumoral lymph and blood vessel density by releasing prostaglandin E2 and stimulating VEGF-C expression in response to $\beta \mathrm{AR}$ stimulation [47]. Finally, another effect that SNS might have on cancer natural history is suppression of natural killer cells, through $\beta \mathrm{AR}$ activity, resulting in an easier development and dissemination of neoplasms [48].

RAAS activation has been shown to strongly associate with an increase of tumor angiogenesis and angiogenetic factor expression, invasiveness, metastasis, and overall poor prognosis [49]. Nevertheless, clinically addressing this interaction using RAAS antagonist led to conflicting results in the past $[50,51]$, even if a large meta-analysis showed a beneficial effect of these therapies on all cancer endpoints [52•]. Indeed, a positive correlation between angiotensin receptor blockers (ARBs) or ACE inhibitors (ACEi) and risk of cancer has been hypothesized, on the basis of some data from the SOLVD and the CHARM studies. The problem in interpretation of these data is the competing risk issue: if HF patients receive life-saving therapies, development of malignancies has more "opportunity" and patients may paradoxically be diagnosed with cancer more frequently [1]. On the other hand, it has been observed that angiotensin II, via its receptor, has a main role in VEGF-dependent angiogenesis and crucial steps in carcinogenesis, including cell migration and proliferation. Hence, angiotensin inhibitors may be potential therapeutics for metastatic renal cell carcinoma [53] or could be added to neoadjuvant therapy with FOLFIRINOX followed by chemoradiotherapy for locally advanced pancreatic cancer [54]. 
Unfortunately, VEGF inhibitors (VEGFi), largely used in many antineoplastic combination therapies for genitourinary and colon-rectal cancers, have considerable cardiovascular side effects, such as cardiomyopathy and arterial hypertension, which can affect up to one out of four patients treated with VEGFi [55, 56].

The role of natriuretic peptides in oncogenesis is also being evaluated [57, 58]. Intriguingly, circulating cardiovascular hormones, such as the $\mathrm{N}$ terminal pro peptide of the brain natriuretic peptide (NT-proBNP), have been shown to be related to cancer disease progression and severity, suggesting the presence of subclinical functional and morphological heart damage, providing hints for HF therapy in cancer patients beyond the focus of prevention of anticancer drug-induced cardiotoxicity [59].

Inflammation also plays a major role in the pathophysiology of both cancer and HF. Indeed, the role of inflammation in carcinogenesis has been extensively studied since the nineteenth century [60], and on the other hand, there is no doubt that a chronic inflammation state can be considered a cardiovascular risk factor [21]. For instance, the inflammatory state is involved in the initiation and progression of atherosclerotic processes $[61 \bullet \bullet$, ultimately leading to thrombosis, which underlies the development of ischemic heart disease [62・•], and $\mathrm{HF}$ itself has been proven to be associated with increased circulating levels of pro-inflammatory cytokines $[63,64$, $65 \cdot$ ], leading to a state of mild chronic systemic inflammation [66]. Also, necrotic post-MI cells have an intense stress response, activating nuclear factor NF-kB [12•], one of the major tumor-promoting mechanism, which induces genes responsible for cell proliferation, survival, angiogenesis, and metastasis $[67,68 \bullet$. It has been demonstrated that clonal hematopoiesis of indeterminate potential (CHIP), defined as the presence of clonal leukocytes with impaired immune proprieties derived by acquired mutation in hematopoietic stem cells, may be associated with increase in CV events and all-cause mortality [69]. The risk of developing CHIP increases with aging, and thus it rarely results in development of hematologic malignancies; it seems to be tightly linked to increased CV events and worse HF prognosis [70, 71].

Interestingly, the Canakinumab Anti-Inflammatory Thrombosis Outcomes (CANTOS) trial showed that IL-1 $\beta$ targeting antibody, canakinumab, not only was able to reduce the rate of recurrence of major adverse cardiovascular events in patients with previous myocardial infarction [72•*] but also was able to lower the risk of incident lung cancer and its mortality rate [73••]. On the other hand, canakinumab did not reduce the incidence of other malignancies [73••]. Unfortunately, in the CANTOS trial, it was not possible to extensively assess the effects of canakinumab on non-small cell lung carcinoma (NSCLC) [73••]. NSCLC patients are being studied in the CANOPY trial, an on-going phase III case-control study that is evaluating canakinumab as a possible antineoplastic treatment for NSCLC in different settings, such as after adjuvant standard chemotherapeutical regiments (CANOPY-A), in association with pembrolizumab and platinum-derived compound (CANOPY-1) and in association with docetaxel (CANOPY-2) [74, 75].

Finally, interesting results from experimental work from Meijers and colleagues [76••] demonstrated that the presence of HF is indeed associated with enhanced tumor growth, independently from hemodynamic impairment, with involvement of cardiac-released factors [76••]. These results have also high translational value, since the authors observed increased plasma levels of their 5 candidate proteins in the plasma of 101 patients with chronic HF compared to 180 healthy patients enrolled in the PREVEND study [17, 77]. Also, increased HF biomarkers, as well as inflammation-related proteins, were predictive of incident cancer independent of cancer risk factors [78].

\section{Cancer in Heart Failure Patients: Clinical Implications}

For clinicians, dealing with HF patients who develop cancer can be challenging, especially when facing possible symptomatologic overlaps between new-onset cancer and preexisting heart dysfunction (that can worsen the already poor outcome of HF patients) and when choosing the best combination of treatments for HF and cancer [1]. There are several clinical implications: new-onset cancer can impair the fragile homeostasis of the HF patients, can increase the risk of developing cardiotoxicity due to antineoplastic treatments, and can limit both oncological and cardiovascular therapeutic options, worsening the prognosis of this subset of patients. In addition, cancer itself can further impair cardiac function [79], by altering patients' electrolyte homeostasis, producing hormonal alterations and worsening endothelial dysfunction and chronic inflammation [1].

Hasin and co-workers also demonstrated that patients with HF that develop cancer have a poorer prognosis compared to non-HF controls [14]. This is probably due to a higher prevalence of comorbidities in HF patients and the superimposed mortality risk derived by the coexistence of both cancer and HF $[80 \bullet$ ]. Cancer can also increase the risk of readmission for $\mathrm{HF}$, further uprising the risk of death for those patients [81]. Banke and colleagues, comparing the incidence of cancer between HF patients and the general background population in Denmark, not only confirmed previous data showing that HF patients have a higher risk of developing new-onset cancer but also found that, after stratifying the population into 3 groups according to age, HF patients aged $<60$ and $60-69$ years old had the same mortality outcome compared to control patients in the groups aged 60-69 and $>70$ years old, respectively [13॰]. These data suggest that the mortality risk derived from cancer superimposed on the one derived for the preexisting $\mathrm{HF}$, dramatically worsening patients' prognosis. Furthermore, the symptoms of new-onset cancer may be masked by HF 
symptoms, and, also, the tumor can affect the already fragile homeostasis of patients with preexisting heart dysfunction [1, 79]. Additionally, the psychological burden must be addressed, considering that both HF and cancer could have a negative impact on the patient's mental status, frequently leading to depression, a well-known cause of increased mortality rate in both diseases $[82,83]$.

Another important issue that needs to be addressed concerns antineoplastic treatment in HF patients. Patients with preexisting HF have a higher risk of developing cardiac toxicities induced by antineoplastic treatments, which can superimpose on an already dysfunctional heart $[1,6 \bullet \bullet, 7 \cdot \bullet, 8]$. Additionally, patients with HF have a higher risk of mortality during anticancer surgery, compared to the non-HF population, which sometimes limits the antineoplastic treatment and affects prognosis $[84 \cdot, 85]$.

It is fundamental for cardiologists and HF specialists to perform a comprehensive evaluation of HF patients who develop cancer, in order to fully assess their characteristics. A full baseline assessment is recommended, including clinical history, ECG, physical examination, blood withdrawal to exclude possible serum alteration (e.g., anemia, hyperglycemia), echocardiography, and any other test deemed necessary by the clinician. In this subset, it is essential to perform a risk-benefit analysis to truly understand what are the best possible treatments available for both cancer and $\mathrm{HF}$ and in order to tailor specific treatments for each patient, taking also into account cancer characteristics and HF stage and comorbidities $[1,86$, $87 \bullet \cdot, 88 \cdot \bullet$. The first steps should be optimization of cardiac therapy and addressing the modifiable comorbidities (e.g., suggesting smoke cessation and diet adjustments, improving diabetes treatments) and, when necessary, treatment of underlying valvular defects or evaluation of residual ischemia $[1,4 \cdot \bullet]$. Correction of metabolic disorders, electrolyte impairments, or any other coexisting alterations that could increase the risk of developing cardiotoxicity induced by antineoplastic treatments is also important $[1,6 \bullet \bullet, 7 \bullet \bullet, 8]$. The process of optimization and up-titration of HF therapy may require even months; this sometimes can lead to a long time latency before starting antineoplastic treatments (e.g., surgery or chemotherapy) [1] and can impair patients' survival. The interplay between cardiologists and oncologists is crucial in this phase, in order to guarantee the best management of the HF patients who develops cancer. It is fundamental to schedule regular follow-ups for HF-cancer patients in order to early identify any changes in HF symptoms that may be suggestive of new-onset cardiotoxicity, and promptly correct any serum alteration or other signs of decompensated HF. Withdrawal of cancer treatments should be avoided as much as possible to guarantee the completion of antineoplastic treatment to HF patient.

Fluid management during chemotherapy administration is another important issue. Cancer patients often are administered with large amount of fluids in order to limit renal adverse reaction induced by antineoplastic drugs [89••]. This approach is dangerous in HF patients, due to the risk of fluid overload, but, on the other hand, HF is often associated with chronic kidney disease, especially in older patients [90]. HF patients should be administered with lower doses of fluids, infusion time should be prolonged, and diuretics could be added/ increased to avoid pulmonary edema or other complications related to volume overload $[1,4 \cdot \bullet]$.

Cancer patients also have an increased risk of developing QT prolongation and atrial fibrillation (AF) [91], which is a wellknown cause of increased mortality risk in HF patients [92]. The possible causes behind new-onset $\mathrm{AF}$ in this subset seem to be thoracic surgery, electrolyte impairment, advanced age, metabolic alterations, and hypoxia [91]. Moreover, AF requires anticoagulation treatment, which may be contraindicated in $\mathrm{HF}$ patients with new-onset cancers, due to the high risk of bleeding (i.e., gastrointestinal malignancies and brain metastases have high bleeding risk [93]). It is also important to periodically interrogate patients' electronic devices, such as implantable defibrillators and pacemakers, with special attention to radiation therapies that can impair device functionality [94•].

Bottomline, it is fundamental for HF patients to be administered the best HF treatments in order to be able to receive the most suitable anticancer therapies: HF should not burden antineoplastic management. Indeed, Gross and colleagues highlighted that patients with HF and colon-rectal cancer are less likely to receive adjuvant chemotherapy and have a worse 5 -year survival outcome when cancer remained untreated, compared to non-HF patients with cancer [95]. On the other hand, another critical issue to be addressed is the risk of undertreating $\mathrm{HF}$ after cancer diagnosis. HF patients usually are administered with a complex therapy and also with other drugs to treat comorbidities, such as diabetes, thyroid dysfunction, and dyslipidemia $[4 \bullet \cdot$. However, the presence of cancer can alter HF patients' homeostasis, leading to temporary changes in HF therapy, with possible reduction and suboptimization. Patients with $\mathrm{HF}$ and cancer can manifest vomiting, diarrhea, or other endocrinological conditions that may affect electrolyte status, forcing cardiologists to reduce important HF treatment medications.

Another important problem is how to manage anticoagulation therapy in HF patients with cancer. It is well known that cancer may have both a pro-thrombotic and a prohemorrhagic effect, depending on the cancer type and its site (e.g., patients with gastrointestinal cancer have a higher risk of major bleeding, especially when administered with anticoagulants [93]). As stated above, AF is a common comorbidity in both $\mathrm{HF}$ and cancer patients, and it is also a possible side effect of some anticancer treatments [91, 92, 94•]. In recent years, direct oral anticoagulants are being preferred to warfarin thanks to their safety profile [96]. Moreover, HF-cancer patients have a higher risk of developing deep venous thrombosis and pulmonary embolisms, as well as central venous catheter thrombosis [96]. For this reason, it is fundamental for the 
cardio-oncology team to stratify the thrombosis/bleeding risk for each $\mathrm{HF}$-cancer patient and decide whether anticoagulation treatment is required and which anticoagulants are to be chosen among low-weight heparin and direct oral anticoagulants, considering among all possible drug interactions $[97 \bullet \bullet]$.

Of notice, patients with active cancer are almost automatically excluded from the heart transplant list, while a careful dialog between cardiologists and oncologists is recommended [98] in order to identify whether the patient is suitable for heart transplantation, identifying life expectancy and prognosis $[1$, 4.•]. Many other invasive treatments for HF are being investigated in the presence of a concomitant cancer [99] diagnosis that shortens patients' life expectancy. For example, device implantation is vetoed when life expectancy is shorter than 1 year [4*0]. On the other hand, treatment with left ventricular assist devices should be considered in patients with concomitant cancer who have a good prognosis ( $\geq 2$ years) $[4 \cdot \bullet, 100]$. However, when considering patients for cardiac transplant or left ventricular devices, it is fundamental to identify the prognosis and the life expectancy, taking also into account cancer types and its specific prognosis. Furthermore, HF patients who undergo heart transplantation will have to be administered with immunosuppressant therapy for life, and this is a well-known risk factor for cancer development. Whether patients with recent malignancies are more exposed to the risk of developing a new tumor with immunosuppressive therapies is still a matter of debate. However, it is clear how every patient with preexisting HF who develops cancer must be treated as a unique case and needs a medical approach tailored to this peculiar condition. Also, clinicians should risk-stratify HF patients in order to identify those who have higher risk of developing cancer and identify screening protocols in order to anticipate cancer diagnosis.

Finally, dexrazoxane may have an important cardioprotective role even in HF patients with new-onset cancer. Dexrazoxane is well known for its cardioprotective effects and has been largely used to treat anthracycline-induced cardiotoxicity [101, 102]. However, there are no studies that evaluate the efficacy and safety of dexrazoxane in HF patients, and, additionally, its cardioprotective effects are limited to anthracyclines, which are still pivotal in many antineoplastic treatments. Indeed, there is urgent need for researching other cardioprotective agents which may counteract and prevent cardiotoxicity induced by drugs other than anthracyclines.

\section{Conclusions}

Recent data show that not only the connection between cancer and HF is stochastic but also these two diseases are deeply linked by common pathophysiological pathways, and the presence of preexisting HF is per se a risk factor for cancer development. The risk of developing cancer in HF patients is higher than in the general population, and management of these patients is burdened by the complexity of these two diseases and their interactions. It may be recommended to consider differential surveillance programs to screen patients with $\mathrm{HF}$ who are at risk for cancer development to anticipate the diagnosis of possible new-onset malignancies. However, further studies on cardiac-secreted factors [78] and their potential utility as cancer biomarkers could help to risk-stratify patients with $\mathrm{HF}$ in terms of their cancer risk.

Clinicians have to face that cancer and HF carry an independent risk of mortality, but also potentially hinder the treatment of one another, with the result being a further increase in mortality, not to speak of the well-known HF risk related to treatment with anticancer drugs that may even worsen the scenario of cancer superimposed to preexisting HF [1]. Moreover, the lack of international guidelines on the correct management of patients affected simultaneously by cancer and HF should be addressed.

In order to overcome these challenges, a close collaboration between cardiologists and oncologists is fundamental to improve the management of these patients, with both specialists understanding the benefits of therapy for HF and cancer, and the risks of withholding or sub-optimally treating either or both diseases. Cardiologists and oncologists could collaborate by creating national or regional cardiotoxicity registries to better evaluate the incidence of cardiac adverse reactions due to antineoplastic treatments and explore the possible presence of other CV side effects still unknown or underdiagnosed.

The prognostic impact of each condition should always be well defined and considered in decision-making [1]. A multidisciplinary approach is encouraged [98] and should include other healthcare professionals, including cardiac rehabilitation, psychology, and palliative care where necessary.

The scientific evidence upon which clinical decisions can be based is very limited, but epidemiology is showing that occurrence of cancer in $\mathrm{HF}$ is an increasingly common problem with an aging population and in the current era of cancer and postmyocardial infarction survivorship. While the SCHOLAR [103] and SAFE-Heart [104••, 105] studies addressed congestive HF that occurred with anthracycline/anti-HER2 treatments as opposed to preexisting HF, they were able to show that most of their cohorts could be medically managed with medical therapy to continue and complete their breast cancer treatments. Likewise, this approach could apply to other populations with preexisting HF with cancer, but would need further data. Further well-designed studies are required to clarify the thresholds at which cancer treatment should not be administered to patients with preexisting $\mathrm{HF}$ and the optimal cardioprotective and surveillance strategies for patients in whom these two worrisome conditions coexist. Clinical trials should be conducted specifically on HF patients who develop cancer, in order to better understand and define clinical course, antineoplastic and HF drug dosages, and possible additional treatment-related side effects that those 
Table 1 Summary of the key points of this review on cancer risk in heart failure

Key points

- In Western countries, cancer and heart failure (HF) are two of the most common diseases in an aging population and are responsible for most of the deaths.

- These two conditions share numerous risk factors, such as obesity, smoking, and hyperglycemia. Furthermore, the link between HF and cancer involves many molecular pathways that characterize HF, suggesting that the presence of HF per se might be a risk factor for developing cancer.

- It has been demonstrated that patients with HF have a higher incidence of cancer compared to the general population. Moreover, patients with $\mathrm{HF}$ and cancer have a poorer prognosis.

- The management of HF patients who develop cancer is complex and requires a constant interplay between cardiologists and oncologists.

patients may face. Moreover, more trials testing anticancer treatment should include a real-world population, which also include patients with many $\mathrm{CV}$ comorbidities to improve current knowledge on the impact that cancer has on preexisting CVDs.

Finally, more attention should be given to prevention of the development of cancer in HF patients, acting on education and information to reduce modifiable common risk factors between cancer and HF (i.e., anti-smoking campaigns, obesity prevention...). Table 1 summarizes the key points discussed above.

Funding Open access funding provided by Università degli Studi di Napoli Federico II within the CRUI-CARE Agreement.

\section{Compliance with Ethical Standards}

Conflict of Interest Alessandra Cuomo, Umberto Attanasio, Riccardo Franco, Francesco Elia, Eliana De Rosa, Michele Russo, and Flora Pirozzi declare no conflict of interest. Valentina Mercurio has received research funding from SIC/MSD. Alessandra Ghigo is a shareholder and board member of Kither Biotech, a spin-off company focused on the development of PI3K inhibitors for airway disease. Pietro Ameri is supported by an investigator-initiated grant from Boehringer Ingelheim; has received speaker's honoraria from Novartis, Servier, Daiichi-Sankyo, Pfizer, Boehringer Ingelheim, AstraZeneca, and Merck Sharp \& Dohme; and has received compensation for service on advisory boards from Novartis, Daiichi-Sankyo, Bayer, Janssen, and GlaxoSmithKline. Carlo G. Tocchetti has received compensation from Alere for service as a consultant and is listed as an inventor on and receives royalties for Canadian Patent No. 2,613,477 (entitled Thiol-Sensitive Positive Inotropes), issued 3 December 2013, owned by Johns Hopkins University (JHU Ref.: C04755-P04755-05).

Human and Animal Rights and Informed Consent This article does not contain any studies with human or animal subjects performed by the authors.

Open Access This article is licensed under a Creative Commons Attribution 4.0 International License, which permits use, sharing, adaptation, distribution and reproduction in any medium or format, as long as you give appropriate credit to the original author(s) and the source, provide a link to the Creative Commons licence, and indicate if changes were made. The images or other third party material in this article are included in the article's Creative Commons licence, unless indicated otherwise in a credit line to the material. If material is not included in the article's Creative Commons licence and your intended use is not permitted by statutory regulation or exceeds the permitted use, you will need to obtain permission directly from the copyright holder. To view a copy of this licence, visit http://creativecommons.org/licenses/by/4.0/.

\section{References}

Papers of particular interest, published recently, have been highlighted as:

- Of importance

•. Of major importance

1. Ameri P, Canepa M, Anker MS, Belenkov Y, Bergler-Klein J, Cohen-Solal A, et al. Cancer diagnosis in patients with heart failure: epidemiology, clinical implications and gaps in knowledge. Eur J Heart Fail. 2018;20:879-87.

2. Anker MS, von Haehling S, Landmesser U, Coats AJS, Anker SD. Cancer and heart failure-more than meets the eye: common risk factors and co-morbidities. Eur J Heart Fail. 2018;20:1382-4.

3. Heidenreich PA, Trogdon JG, Khavjou OA, Butler J, Dracup K, Ezekowitz MD, et al. Forecasting the future of cardiovascular disease in the United States: a policy statement from the American Heart Association. Circulation. 2011;123:933-44.

4.• Ponikowski P, Voors AA, Anker SD, Bueno H, Cleland JGF, Coats AJS, et al. 2016 ESC guidelines for the diagnosis and treatment of acute and chronic heart failure. Eur Heart J. 2016;37: 2129-200. https://doi.org/10.1093/eurheartj/ehw128. Guidelines for the management of acute and chronic heart failure.

5. Benjamin EJ, Virani SS, Callaway CW, Chamberlain AM, Chang AR, Cheng S, et al. Heart disease and stroke statistics-2018 update: a report from the American Heart Association. Circulation. 2018;137: e67-e492. https://doi.org/10.1161/CIR.0000000000000558.

6.• Zamorano JL, Lancellotti P, Rodriguez Muñoz D, Aboyans V, Asteggiano R, Galderisi M, et al. 2016 ESC position paper on cancer treatments and cardiovascular toxicity developed under the auspices of the ESC Committee for Practice Guidelines. Eur Heart J. 2016;37:2768-801. https://doi.org/10.1093/eurheartj/ ehw211. The first clinical position paper from the European Society of Cardiology expressly dedicated to cancer treatments and cardiotoxicity.

7.• Armenian SH, Lacchetti C, Barac A, Carver J, Constine LS, Denduluri N, et al. Prevention and monitoring of cardiac dysfunction in survivors of adult cancers: American Society of Clinical Oncology clinical practice guideline. J Clin Oncol. 2017;35:893911. https://doi.org/10.1200/JCO.2016.70.5400. Guidelines published by the American Society of Clinical Oncology; the authors state how to manage cardiovascular diseases induced by antineoplastic treatment.

8. Denlinger CS, Sanft T, Baker KS, Broderick G, DemarkWahnefried W, Friedman DL, et al. Survivorship, Version 2.2018, NCCN clinical practice guidelines in oncology. J Natl Compr Cancer Netw. 2018;16:1216-47.

9. Moslehi J, Fujiwara K, Guzik T. Cardio-oncology: a novel platform for basic and translational cardiovascular investigation driven by clinical need. Cardiovasc Res. 2019;115:819-23.

10. Lenihan DJ, Hartlage G, DeCara J, et al. Cardio-oncology training: a proposal from the International Cardioncology Society and Canadian Cardiac Oncology Network for a New Multidisciplinary 
Specialty. J Card Fail. 2016;22(6):465-71. https://doi.org/10. 1016/j.cardfail.2016.03.012.

11. Aboumsallem JP, Moslehi J, de Boer RA. Reverse cardio-oncology: cancer development in patients with cardiovascular disease. J Am Heart Assoc. 2020;9:e013754.

12. Hasin T, Iakobishvili Z, Weisz G. Associated risk of malignancy in patients with cardiovascular disease: evidence and possible mechanism. Am J Med. 2017;130:780-5. https://doi.org/10. 1016/j.amjmed.2017.02.024. Interesting study on the risk of developing cancer in a preexisting heart failure population. The authors demonstrated that patients with heart failure have a higher risk of developing cancer.

13. Banke A, Schou M, Videbæk L, Møller JE, Torp-Pedersen C, Gustafsson F, et al. Incidence of cancer in patients with chronic heart failure: a long-term follow-up study. Eur J Heart Fail. 2016;18:260-6. Interesting population study on the risk of developing new-onset cancer in HF patients. They also found that patients with heart failure and cancer have a higher mortality rate compared to controls matched for age and sex.

14. Hasin T, Gerber Y, McNallan SM, Weston SA, Kushwaha SS, Nelson TJ, et al. Patients with heart failure have an increased risk of incident cancer. J Am Coll Cardiol. 2013;62:881-6.

15. Hasin T, Gerber Y, Weston SA, Jiang R, Killian JM, Manemann $\mathrm{SM}$, et al. Heart failure after myocardial infarction is associated with increased risk of cancer. J Am Coll Cardiol. 2016;68:265-71. https://doi.org/10.1016/j.jacc.2016.04.053. In this paper, the authors demonstrated that the risk of cancer in patients with heart failure due to previous myocardia infarction is higher than the general population.

16. Carpeggiani C, Landi P, Michelassi C, Andreassi MG, Sicari R, Picano E. Stress echocardiography positivity predicts cancer death. J Am Heart Assoc. 2017;6:e007104.

17. Hillege HL, Janssen WMT, Bak AAA, Diercks GFH, Grobbee DE, Crijns HJGM, et al. Microalbuminuria is common, also in a nondiabetic, nonhypertensive population, and an independent indicator of cardiovascular risk factors and cardiovascular morbidity. J Intern Med. 2001;249:519-26. https://doi.org/10.1046/j. 1365-2796.2001.00833.x.

18. Casparie M, Tiebosch ATMG, Burger G, Blauwgeers H, Van De Pol A, Van Krieken JHJM, et al. Pathology databanking and biobanking in The Netherlands, a central role for PALGA, the nationwide histopathology and cytopathology data network and archive. Cell Oncol. 2007. https://doi.org/10.1155/2007/971816.

19. Cramer L, Hildebrandt B, Kung T, Wichmann K, Springer J, Doehner W, et al. Cardiovascular function and predictors of exercise capacity in patients with colorectal cancer. J Am Coll Cardiol. 2014;64:1310-9.

20. de Boer RA, Meijers WC, van der Meer P, van Veldhuisen DJ. Cancer and heart disease: associations and relations. Eur J Heart Fail. 2019;21:1515-25.

21. van't Klooster CC, Ridker PM, Hjortnaes J, van der Graaf Y, Asselbergs FW, Westerink J, et al. The relation between systemic inflammation and incident cancer in patients with stable cardiovascular disease: a cohort study. Eur Heart J. 2019;40:3901-9.

22. Olinski R, Siomek A, Rozalski R, Gackowski D, Foksinski M, Guz J, et al. Oxidative damage to DNA and antioxidant status in aging and age-related diseases. Acta Biochim Pol. 2007;54:11-26. https://doi.org/10.18388/abp.2007_3265.

23. Liguori I, Russo G, Curcio F, Bulli G, Aran L, Della-Morte D, et al. Oxidative stress, aging, and diseases. Clin Interv Aging. 2018; Volume 13:757-72. https://doi.org/10.2147/CIA.S158513.

24. Abete P, Napoli C, Santoro G, Ferrara N, Tritto I, Chiariello M, et al. Age-related decrease in cardiac tolerance to oxidative stress. J Mol Cell Cardiol. 1999;31:227-36. https://doi.org/10.1006/ jmcc.1998.0862.
25. Liberale L, Montecucco F, Tardif J-C, Libby P, Camici GG. Inflamm-ageing: the role of inflammation in age-dependent cardiovascular disease. Eur Heart J. 2020;41:2974-82. https://doi. org/10.1093/eurheartj/ehz961. In this review, the authors explore the connections between aging, oxidative stress, and both cancer and cardiovascular diseases. In recent years, a lot of attention has been given to the possible role of oxidative stress as a driver for the onset of cancer in heart failure patients.

26. Sasco AJ, Secretan MB, Straif K. Tobacco smoking and cancer: a brief review of recent epidemiological evidence. Lung Cancer. 2004;45:S3-9. https://doi.org/10.1016/j.lungcan.2004.07.998.

27. Eckel RH, Grundy SM, Zimmet PZ. The metabolic syndrome. Lancet. 2005;365:1415-28. https://doi.org/10.1016/S01406736(05)66378-7.

28. Stattin P, Björ O, Ferrari P, Lukanova A, Lenner P, Lindahl B, et al. Prospective study of hyperglycemia and cancer risk. Diabetes Care. 2007;30:561-7.

29. Yao X, Tian Z. Dyslipidemia and colorectal cancer risk: a metaanalysis of prospective studies. Cancer Causes Control. 2015;26: 257-68.

30. Lauby-Secretan B, Scoccianti C, Loomis D, Grosse Y, Bianchini F, Straif K. Body fatness and cancer-viewpoint of the IARC working group. N Engl J Med. 2016;375:794-8. https://doi.org/10. 1056/NEJMsr1606602.

31. Ecker BL, Lee JY, Sterner CJ, et al. Impact of obesity on breast cancer recurrence and minimal residual disease. Breast Cancer Res. 2019;21:1-16.

32. Pajares B, Pollán M, Martín M, et al. Obesity and survival in operable breast cancer patients treated with adjuvant anthracyclines and taxanes according to pathological subtypes: a pooled analysis. Breast Cancer Res. 2013;15:1-14.

33. Sakamoto M, Hasegawa T, Asakura M, Kanzaki H, Takahama H, Amaki M, et al. Does the pathophysiology of heart failure prime the incidence of cancer? Hypertens Res. 2017;40:831-6. https:// doi.org/10.1038/hr.2017.45.

34. Bertero E, Ameri P, Maack C. Bidirectional relationship between cancer and heart failure: old and new issues in cardio-oncology. Card Fail Rev. 2019;5:106-11.

35. Bertero E, Canepa M, Maack C, Ameri P. Linking heart failure to cancer. Circulation. 2018;138:735-42.

36. Hara MR, Kovacs JJ, Whalen EJ, Rajagopal S, Strachan RT, Grant W, et al. A stress response pathway regulates DNA damage through $\beta 2$-adrenoreceptors and $\beta$-arrestin-1. Nature. 2011;477: 349-53. https://doi.org/10.1038/nature10368.

37. Zhang D, Ma QY, Hu HT, Zhang M. $\beta 2$-adrenergic antagonists suppress pancreatic cancer cell invasion by inhibiting CREB, NFKB and AP-1. Cancer Biol Ther. 2010;10:19-29. https://doi. org/10.4161/cbt.10.1.11944.

38. Hassan S, Karpova Y, Baiz D, Yancey D, Pullikuth A, Flores A, et al. Behavioral stress accelerates prostate cancer development in mice. J Clin Invest. 2013. https://doi.org/10.1172/JCI63324.

39. Sood AK, Armaiz-Pena GN, Halder J, Nick AM, Stone RL, Hu $\mathrm{W}$, et al. Adrenergic modulation of focal adhesion kinase protects human ovarian cancer cells from anoikis. J Clin Invest. 2010;120: 1515-23. https://doi.org/10.1172/JCI40802.

40. Coelho M, Soares-Silva C, Brandão D, Marino F, Cosentino M, Ribeiro L. $\beta$-Adrenergic modulation of cancer cell proliferation: available evidence and clinical perspectives. J Cancer Res Clin Oncol. 2017;143:275-91.

41. Barron TI, Connolly RM, Sharp L, Bennett K, Visvanathan K. Beta blockers and breast cancer mortality: a population-based study. J Clin Oncol. 2011;29:2635-44.

42. Sysa-Shah P, Tocchetti CG, Gupta M, Rainer PP, Shen X, Kang $\mathrm{BH}$, et al. Bidirectional cross-regulation between ErbB2 and $\beta$ adrenergic signalling pathways. Cardiovasc Res. 2016;109:358- 
73. https://doi.org/10.1093/cvr/cvv274. Important paper showing experimental data on a possible link between 2 fundamental regulatory systems ( $\beta$ AR and HER2).

43. Avila MS, Ayub-Ferreira SM, de Barros Wanderley Junior MR, et al. Carvedilol for prevention of chemotherapy related cardiotoxicity. J Am Coll Cardiol. 2018;71:2281-90. https://doi. org/10.1016/j.jacc.2018.02.049.

44. Guglin M, Krischer J, Tamura R, Fink A, Bello-matricaria L, Mccaskill-stevens W, et al. Randomized trial of lisinopril versus carvedilol to prevent trastuzumab cardiotoxicity in patients with breast cancer. 2019. https://doi.org/10.1016/j.jacc.2019.03.495. This clinical paper somehow confirms the experimental findings of Sysa Shah et al. CVR 2016.

45. Cole SW, Nagaraja AS, Lutgendorf SK, Green PA, Sood AK. Sympathetic nervous system regulation of the tumour microenvironment. Nat Rev Cancer. 2015;15:563-72. https://doi.org/10. 1038/nrc3978.

46. Galdiero MR, Garlanda C, Jaillon S, Marone G, Mantovani A. Tumor associated macrophages and neutrophils in tumor progression. J Cell Physiol. 2013;228:1404-12.

47. Armaiz-Pena GN, Gonzalez-Villasana V, Nagaraja AS, Rodriguez-Aguayo C, Sadaoui NC, Stone RL, et al. Adrenergic regulation of monocyte chemotactic protein 1 leads to enhanced macrophage recruitment and ovarian carcinoma growth. Oncotarget. 2015;6:4266-73.

48. Shakhar G, Ben-Eliyahu S. In vivo beta-adrenergic stimulation suppresses natural killer activity and compromises resistance to tumor metastasis in rats. J Immunol. 1998;160(7):3251-8.

49. George AJ, Thomas WG, Hannan RD. The renin-angiotensin system and cancer: old dog, new tricks. Nat Rev Cancer. 2010;10: 745-59. https://doi.org/10.1038/nrc2945.

50. Wang KL, Liu CJ, Chao TF, Huang CM, Wu CH, Chen TJ, et al. Long-term use of angiotensin II receptor blockers and risk of cancer: a population-based cohort analysis. Int J Cardiol. 2013;167: 2162-6. https://doi.org/10.1016/j.ijcard.2012.05.096.

51. Sipahi I, Debanne SM, Rowland DY, Simon DI, Fang JC. Angiotensin-receptor blockade and risk of cancer: meta-analysis of randomised controlled trials. Lancet Oncol. 2010;11:627-36. https://doi.org/10.1016/S1470-2045(10)70106-6.

52. Sun H, Li T, Zhuang R, Cai W, Zheng Y. Do renin-angiotensin system inhibitors influence the recurrence, metastasis, and survival in cancer patients? Evidence from a meta-analysis including 55 studies. Medicine (Baltimore). 2017;96:e6394. https://doi.org/10. 1097/MD.0000000000006394. In this review, the authors explore the possible clinical role of renin-angiotensin inhibitors in the subset of cancer patient, considering that alterations of the renin-angiotensin-aldosterone system have been linked to cancer development.

53. McDermott DF, Cheng S-C, Signoretti S, et al. The high-dose aldesleukin 'select' trial: a trial to prospectively validate predictive models of response to treatment in patients with metastatic renal cell carcinoma. Clin Cancer Res. 2015;21:561-8.

54. Murphy JE, Wo JY, Ryan DP, Clark JW, Jiang W, Yeap BY, et al. Total neoadjuvant therapy with FOLFIRINOX in combination with losartan followed by chemoradiotherapy for locally advanced pancreatic cancer: a phase 2 clinical trial. JAMA Oncol. 2019;5: 1020-7.

55. Tocchetti CG, Gallucci G, Coppola C, Piscopo G, Cipresso C, Maurea $\mathrm{C}$, et al. The emerging issue of cardiac dysfunction induced by antineoplastic angiogenesis inhibitors. Eur J Heart Fail. 2013;15(5):482-9. https://doi.org/10.1093/eurjhf/hft008.

56. Pandey AK, Singhi EK, Arroyo JP, Ikizler TA, Gould ER, Brown $\mathrm{J}$, et al. Mechanisms of VEGF (vascular endothelial growth factor) inhibitor-associated hypertension and vascular disease. Hypertension. 2018;71:e1-8.
57. Kong X, Wang X, Xu W, Behera S, Hellermann G, Kumar A, et al. Natriuretic peptide receptor a as a novel anticancer target. Cancer Res. 2008;68:249-56. https://doi.org/10.1158/0008-5472. CAN-07-3086.

58. Nojiri T, Hosoda H, Tokudome T, Miura K, Ishikane S, Otani K, et al. Atrial natriuretic peptide prevents cancer metastasis through vascular endothelial cells. Proc Natl Acad Sci U S A. 2015;112: 4086-91. https://doi.org/10.1073/pnas.1417273112.

59. Pavo N, Raderer M, Hulsmann M, et al. Cardiovascular biomarkers in patients with cancer and their association with allcause mortality. Heart. 2015;101:1874-80.

60. Lesterhuis WJ, Haanen JBAG, Punt CJA. Cancer immunotherapy-revisited. Nat Rev Drug Discov. 2011;10:591-600.

61.• Libby P, Sidlow R, Lin AE, et al. Clonal hematopoiesis: crossroads of aging, cardiovascular disease, and cancer: JACC review topic of the week. J Am Coll Cardiol. 2019;74:567-77. Very timely paper on novel insights into clonal hematopoiesis and immunity linking aging, cardiovascular disease, and cancer.

62.• Koene RJ, Prizment AE, Blaes A, Konety SH. Shared risk factors in cardiovascular disease and cancer. Circulation. 2016;133:1104-14. https://doi.org/10.1161/CIRCULATIONAHA.115.020406. This review explore the common risk factors between cancer and heart failure, analyzing current litterature and epidemiological data.

63. Levine B, Kalman J, Mayer L, Fillit HM, Packer M. Elevated circulating levels of tumor necrosis factor in severe chronic heart failure. N Engl J Med. 1990;323:236-41. https://doi.org/10.1056/ NEJM199007263230405.

64. Testa M, Yeh M, Lee P, Fanelli R, Loperfido F, Berman JW, et al. Circulating levels of cytokines and their endogenous modulators in patients with mild to severe congestive heart failure due to coronary artery disease or hypertension. J Am Coll Cardiol. 1996;28:964-71. https://doi.org/10.1016/S0735-1097(96)002689.

65. Torre-Amione G, Kapadia S, Lee J, Durand JB, Bies RD, Young $\mathrm{JB}$, et al. Tumor necrosis factor- $\alpha$ and tumor necrosis factor receptors in the failing human heart. Circulation. 1996;93:704-11. https://doi.org/10.1161/01.CIR.93.4.704. Very comprehensive paper linking heart failure and cancer through the analysis of common risk factors.

66. Suthahar N, Meijers WC, Silljé HHW, de Boer RA. From inflammation to fibrosis-molecular and cellular mechanisms of myocardial tissue remodelling and perspectives on differential treatment opportunities. Curr Heart Fail Rep. 2017;14:235-50.

67. Chaturvedi MM, Sung B, Yadav VR, Kannappan R, Aggarwal BB. NF- $\mathrm{KB}$ addiction and its role in cancer: one size does not fit all. Oncogene. 2011;30:1615-30. https://doi.org/10.1038/onc. 2010.566.

68. Meijers WC, De Boer RA. Common risk factors for heart failure and cancer. Cardiovasc Res. 2019;115:844-53. Very comprehensive paper linking heart failure and cancer through the analysis of common risk factors.

69. Yura Y, Sano S, Walsh K. Clonal hematopoiesis: a new step linking inflammation to heart failure. JACC Basic Transl Sci. 2020;5:196-207.

70. Dorsheimer L, Assmus B, Rasper T, Ortmann CA, Ecke A, Abouel-Ardat K, et al. Association of mutations contributing to clonal hematopoiesis with prognosis in chronic ischemic heart failure. JAMA Cardiol. 2019:4:25-33.

71. Jaiswal S, Natarajan P, Silver AJ, Gibson CJ, Bick AG, Shvartz E, et al. Clonal hematopoiesis and risk of atherosclerotic cardiovascular disease. N Engl J Med. 2017;377:111-21.

72.• Ridker PM, Everett BM, Thuren T, MacFadyen J, Chang WH, Ballantyne C, et al. Antiinflammatory therapy with canakinumab for atherosclerotic disease. N Engl J Med. 2017;377:1119-31. https://doi.org/10.1056/NEJMoa1707914. The authors 
demonstrate that treating patients with canakinumab, an interleukin-1beta-targeting antibody, reduces the incidence of recurrent major adverse cardiovascular events in patients with previous myocardial infarction.

73.•• Ridker PM, MacFadyen JG, Thuren T, et al. Effect of interleukin$1 \beta$ inhibition with canakinumab on incident lung cancer in patients with atherosclerosis: exploratory results from a randomised, double-blind, placebo-controlled trial. Lancet. 2017;390:183342. https://doi.org/10.1016/S0140-6736(17)32247-X. In this manuscript, the authors demonstrated that treatment with canakinumab reduces also the rate of incident lung cancer.

74. Paz-Ares LG, Garon EB, Ardizzoni A, Barlesi F, Cho BC, Castro $\mathrm{G}$, et al. The CANOPY program: canakinumab in patients (pts) with non-small cell lung cancer (NSCLC). J Clin Oncol. 2019;37: TPS9124.

75. Garon EB, Ardizzoni A, Barlesi F, Cho BC, de Marchi P, Goto Y, et al. CANOPY-A: a phase III study of canakinumab as adjuvant therapy in patients with surgically resected non-small cell lung cancer (NSCLC). J Clin Oncol. 2019;37:TPS8570.

76.• Meijers WC, Maglione M, Bakker SJL, et al. Heart failure stimulates tumor growth by circulating factors. Circulation. 2018;138: 678-91. This pivotal manuscript helps understanding the link between heart failure and cancer. The authors showed for the first time that failing hearts favor cancerogenesis by demonstrating that HF mice develop cancer by means of cardiacsecreted factors, regardless of the hemodynamics of the failing heart.

77. Schroten NF, Ruifrok WPT, Kleijn L, et al. Short-term vitamin D3 supplementation lowers plasma renin activity in patients with stable chronic heart failure: an open-label, blinded end point, randomized prospective trial (VitD-CHF trial). Am Heart J. 2013;166:357-364.e2.

78. Kitsis RN, Riquelme JA, Lavandero S. Heart disease and cancer: are the two killers colluding? Circulation. 2018;138:692-5.

79. Musolino V, Palus S, Latouche C, Gliozzi M, Bosco F, Scarano F, et al. Cardiac expression of neutrophil gelatinase-associated lipocalin in a model of cancer cachexia-induced cardiomyopathy. ESC Heart Fail. 2019;6:89-97.

80.• Mamas MA, Sperrin M, Watson MC, Coutts A, Wilde K, Burton $\mathrm{C}$, et al. Do patients have worse outcomes in heart failure than in cancer? A primary care-based cohort study with 10-year follow-up in Scotland. Eur J Heart Fail. 2017;19:1095-104. https://oi.org/ $10.1002 /$ ejhf.822. In this manuscript, the authors explore whether heart failure patients have a worse outcome compared to cancer patients, showing that cardiovascular diseases have a higher mortality rate.

81. Omersa D, Farkas J, Erzen I, Lainscak M. National trends in heart failure hospitalization rates in Slovenia 2004-2012. Eur J Heart Fail. 2016;18:1321-8.

82. Newhouse A, Jiang W. Heart failure and depression. Heart Fail Clin. 2014;10:295-304.

83. Sotelo JL, Musselman D, Nemeroff C. The biology of depression in cancer and the relationship between depression and cancer progression. Int Rev Psychiatry. 2014;26:16-30.

84. Smit-Fun V, Buhre WF. The patient with chronic heart failure undergoing surgery. Curr Opin Anaesthesiol. 2016;29:391-6. This manuscript highlights the possible complications that may occur when dealing with heart failure-cancer patients who need to undergo surgery. They have an increased risk of perisurgery mortality.

85. Kravchenko J, Berry M, Arbeev K, Lyerly HK, Yashin A, Akushevich I. Cardiovascular comorbidities and survival of lung cancer patients: Medicare data based analysis. Lung Cancer. 2015;88:85-93.

86. Pareek N, Cevallos J, Moliner P, Shah M, Tan LL, Chambers V, et al. Activity and outcomes of a cardio-oncology service in the
United Kingdom-a five-year experience. Eur J Heart Fail. 2018;20:1721-31.

87.• Lancellotti P, Suter TM, López-Fernández T, et al. Cardiooncology services: rationale, organization, and implementation: a report from the ESC Cardio-Oncology council. Eur Heart J. 2019;40:1756-63. In this manuscript, the authors summarize current knowledge on cardio-oncology and hypothesize possible management behaviors in order to guarantee cancer patients with the best possible care, according to their cardiovascular risk status.

88.• Hayek SS, Ganatra S, Lenneman C, Scherrer-Crosbie M, Leja M, Lenihan DJ, et al. Preparing the cardiovascular workforce to care for oncology patients: JACC review topic of the week. J Am Coll Cardiol. 2019;73(17):2226-35. https://doi.org/10.1016/j.jacc. 2019.02.041. In this manuscript, the authors summarize current knowledge on cardio-oncology and hypothesize possible management behaviors in order to guarantee cancer patients with the best possible care, according to their cardiovascular risk status.

89.• Cosmai L, Porta C, Gallieni M, Perazella MA. Onco-nephrology: a decalogue. Nephrol Dial Transplant. 2016;31:515-9. This paper gives some interesting cue on the management of cancer patients with high risk of developing nephrotoxicity induced by chemotherapy.

90. Schefold JC, Filippatos G, Hasenfuss G, Anker SD, Von Haehling S. Heart failure and kidney dysfunction: epidemiology, mechanisms and management. Nat Rev Nephrol. 2016;12:610-23.

91. Farmakis D, Parissis J, Filippatos G. Insights into onco-cardiology: atrial fibrillation in cancer. J Am Coll Cardiol. 2014;63:94553.

92. Mamas MA, Caldwell JC, Chacko S, Garratt CJ, Fath-Ordoubadi F, Neyses L. A meta-analysis of the prognostic significance of atrial fibrillation in chronic heart failure. Eur J Heart Fail. 2009;11:676-83.

93. Angelini DE, Radivoyevitch T, McCrae KR, Khorana AA. Bleeding incidence and risk factors among cancer patients treated with anticoagulation. Am J Hematol. 2019;94:780-5.

94. Viganego F, Singh R, Fradley MG. Arrhythmias and other electrophysiology issues in cancer patients receiving chemotherapy or radiation. Curr Cardiol Rep. 2016;18:52. https://doi.org/10.1007/ s11886-016-0730-0. In this manuscript, the authors suggest to perform periodical implantable device interrogations in order to avoid device mulfunctions due to radiation therapy or other anticancer treatment that can induce arrhythmias.

95. Gross CP, McAvay GJ, Guo Z, Tinetti ME. The impact of chronic illnesses on the use and effectiveness of adjuvant chemotherapy for colon cancer. Cancer. 2007;109:2410-9.

96. Park DY, Khorana AA. Risks and benefits of anticoagulation in cancer and noncancer patients. Semin Thromb Hemost. 2019;45: 629-37.

97.• Kraaijpoel N, Di Nisio M, Mulder FI, et al. Clinical impact of bleeding in cancer-associated venous thromboembolism: results from the Hokusai VTE cancer study. Thromb Haemost. 2018;118:1439-49. In this paper, the authors provide pivotal information on the use of edoxaban in cancer patients used to prevent thromboembolism and pulmonary embolism. This is the first study conducted on a direct oral anticoagulant in cancer subset.

98. Meijers WC, Moslehi JJ. Need for multidisciplinary research and data-driven guidelines for the cardiovascular care of patients with cancer. JAMA. 2019;322:1775-6. https://doi.org/10.1001/jama. 2019.17415.

99. Singh JP, Solomon SD, Fradley MG, Barac A, Kremer KA, Beck $\mathrm{CA}$, et al. Association of cardiac resynchronization therapy with change in left ventricular ejection fraction in patients with 
chemotherapy-induced cardiomyopathy. JAMA. 2019;322(18): 1799-805. https://doi.org/10.1001/jama.2019.16658.

100. Feldman D, Pamboukian SV, Teuteberg JJ, Birks E, Lietz K, Moore SA, et al. The 2013 International Society for Heart and Lung Transplantation guidelines for mechanical circulatory support: executive summary. J Heart Lung Transplant. 2013;32:15787.

101. Varricchi G, Ameri P, Cadeddu C, et al. Antineoplastic druginduced cardiotoxicity: a redox perspective. Front Physiol. 2018;9:1-18.

102. Kollárová-Brázdová P, Jirkovská A, Karabanovich G, Pokorná Z, Bavlovič Piskáčková $\mathrm{H}$, Jirkovský E, et al. Investigation of structure-activity relationships of dexrazoxane analogues reveals topoisomerase II $\beta$ interaction as a prerequisite for effective protection against anthracycline cardiotoxicity. J Pharmacol Exp Ther. 2020;373:402-15. https://doi.org/10.1124/jpet.119.264580.

103. Leong DP, Cosman T, Alhussein MM, Tyagi NK, Karampatos S, Barron CC, et al. Safety of continuing trastuzumab despite mild cardiotoxicity: a phase I trial. J Am Coll Cardiol CardioOncol. 2019;1:1-10

104.• Lynce F, Barac A, Tan MT, Asch FM, Smith KL, Dang C, et al. SAFE-HEaRt: rationale and design of a pilot study investigating cardiac safety of HER2 targeted therapy in patients with HER2positive breast cancer and reduced left ventricular function. Oncologist. 2017;22:518-25. This is an important study designed to verify safety of antineoplastic drugs specifically in congestive HF that occurred with anthracycline/anti-HER2 treatments.

105. Lynce F, Barac A, Geng X, Dang C, Yu AF, Smith KL, et al. Prospective evaluation of the cardiac safety of HER2-targeted therapies in patients with HER2-positive breast cancer and compromised heart function: the SAFE-HEaRt study. Breast Cancer Res Treat. 2019;175:595-603.

Publisher's Note Springer Nature remains neutral with regard to jurisdictional claims in published maps and institutional affiliations. 